\title{
A REPORT ON LEVELLING SURVEY
}

\section{By}

Mala Babagana Gutti

B.Eng. Student, Department of Civil and Water Resources Engineering,

University of Maiduguri, Maiduguri, Nigeria

Email: malabgutti@gmail.com

November, 2015 


\section{ENGINEERING SURVEY}

\section{Introduction to Surveying}

Surveying is the techniques, profession and science of determining the terrestrial or threedimensional position of points, distances and angles between them. It is done in order to achieve the following objectives:

- To determine, measure and represent land, three-dimensional objects, points-fields and trajectories;

- To assemble and interpret land and geographically related information,

- To use that information for planning and efficient administration of land, sea and any structures there on; and

- To conduct research into the above practices and to develop them.

\section{Principles of Surveying}

The following are the general principles guiding every survey:

1. An initial frame work before observing.

2. Planning.

3. The need to ensure that sufficient independent checks are incorporated into survey to eliminate or minimize errors.

4. Field work.

5. Computations.

6. Plotting.

7. Safe guarding. 


\section{LEVELLING SURVEY}

\section{Introduction}

Levelling is the measurement of geodetic height using an optical levelling instrument and a level staff having a numbered scale. It is carried out in order to determine differences in elevation between points on the ground.

\section{Objectives}

- Find elevation of a given point with respect to the given or assumed datum.

- Establish a point at a given elevation with respect to the given or assumed datum.

- To help students identify compass surveying and be able to conduct the survey.

\section{Guidelines}

The following guide lines will help a surveyor to eliminate errors resulting from any line of sight in his/her work:

1. Back sight and fore sight should be equal in distance.

2. The length of sight should be kept less than $100 \mathrm{~m}$.

3. Always commence and finish a level run on a known datum or benchmark and close the level traverse; this enables the level run to be checked.

\section{Instruments Used}

1. The Level.

2. The Level Staff.

3. Steel Tape $(50 \mathrm{~m})$. 
4. The Tripod Stand.

\section{Procedure}

a. Set up the levelling instrument at level position 1 .

b. Hold the staff vertically on the datum and take a reading. This reading will be the back sight, because it is the first staff reading after setting the instrument.

c. Move the staff to point $\mathrm{A}$ and take a reading. This will be an intermediate sight.

d. Move the staff to point B and take a reading. This will also be an intermediate sight.

e. Move the staff to point $\mathrm{C}$ and take a reading. This will be an intermediate sight.

f. Move the staff to point $\mathrm{D}$ and take a reading. This will be a fore sight, because after this reading the level will be moved.

g. The distance between the stations should be measured and recorded into the field book as well.

h. Set up the level at level position 2 and level the staff at point D, then take a reading. This will be a back sight.

i. Move the staff to point $\mathrm{E}$ and take a reading. This will be an intermediate sight.

j. Move the staff to point $\mathrm{F}$ and take a reading. This will be a fore sight, because after this reading the level will be moved.

k. Now move the level to level position 3 and leave the staff at point F.

1. Repeat the above procedure until you reached your destination point. 


\section{Site Description}

\section{- Start Point:}

At the start point of my exercise I used the GPS to obtained the reduced level as $327.100 \mathrm{~m}$. I started level by using the center line of the drainage behind Computer Engineering Department and the drainage measures $0.2 \mathrm{~m}$ in to in. The levelling exercise started at the engineering complex.

- Along the way down to Gate 5:

There were trees, the ground is undulating except for those places that have been graded with a laterite sub-grade, there were utility lines (electric line of supply) and local farm areas along. The width of the roads that have not been graded was varying from $3.8 \mathrm{~m}$ to $4.1 \mathrm{~m}$ and the width of the asphaltic road was $10.6 \mathrm{~m}$ with a median of $0.6 \mathrm{~m}$ and each side has two lanes equivalent to $5 \mathrm{~m}$.

\section{- End Point:}

At the end point of my exercise I also obtained another reduced level as $327.100 \mathrm{~m}$. Stopped on the center line of the drainage in front of Gate which is face south ways. The drainage has a measurement of $1.1 \mathrm{~m}$ in to in, it has a height of $1.0 \mathrm{~m}$, it is $48.67 \mathrm{~m}$ from the road. And there were also electric lines, trees, and local farm areas. 


\section{Result and Discussion}

The following are the data obtained at site during the practical exercise from Engineering Complex to Gate 5.

\begin{tabular}{|c|c|c|c|c|c|c|c|}
\hline STN & B.S & I.S & F.S & RISE & FALL & R.L & REMARK \\
\hline \multirow[t]{2}{*}{$\mathrm{CP}_{1}$} & 0.225 & & & & & 327.100 & TBM 327.100 \\
\hline & & 0.885 & & 1.340 & & 328.440 & \\
\hline \multirow[t]{3}{*}{$\mathrm{CP}_{2}$} & 0.978 & & 0.710 & 0.175 & & 328.615 & \\
\hline & & 1.468 & & & 0.490 & 328.125 & \\
\hline & & 1.020 & & 0.448 & & 328.573 & \\
\hline \multirow[t]{3}{*}{$\mathrm{CP}_{3}$} & 0.799 & & 0.388 & 0.632 & & 329.205 & \\
\hline & & 1.012 & & & 0.213 & 328.995 & \\
\hline & & 0.662 & & 0.350 & & 329.342 & \\
\hline \multirow[t]{2}{*}{$\mathrm{CP}_{4}$} & 0.999 & & 0.261 & 0.401 & & 329.743 & \\
\hline & & 1.599 & & & 0.600 & 329.143 & \\
\hline \multirow[t]{3}{*}{$\mathrm{CP}_{5}$} & 0.735 & & 0.744 & 0.855 & & 329.998 & \\
\hline & & 0.831 & & & 0.960 & 329.038 & \\
\hline & & 0.910 & & & 0.076 & 328.962 & \\
\hline \multirow[t]{3}{*}{$\mathrm{CP}_{6}$} & 0.585 & & 0.720 & 0.190 & & 329.152 & \\
\hline & & 0.999 & & & 0.414 & 328.738 & \\
\hline & & 1.089 & & & 0.090 & 328.648 & \\
\hline \multirow[t]{2}{*}{$\mathrm{CP}_{7}$} & 1.210 & & 0.691 & 0.398 & & 329.046 & \\
\hline & & 1.230 & & & 0.020 & 329.026 & \\
\hline
\end{tabular}




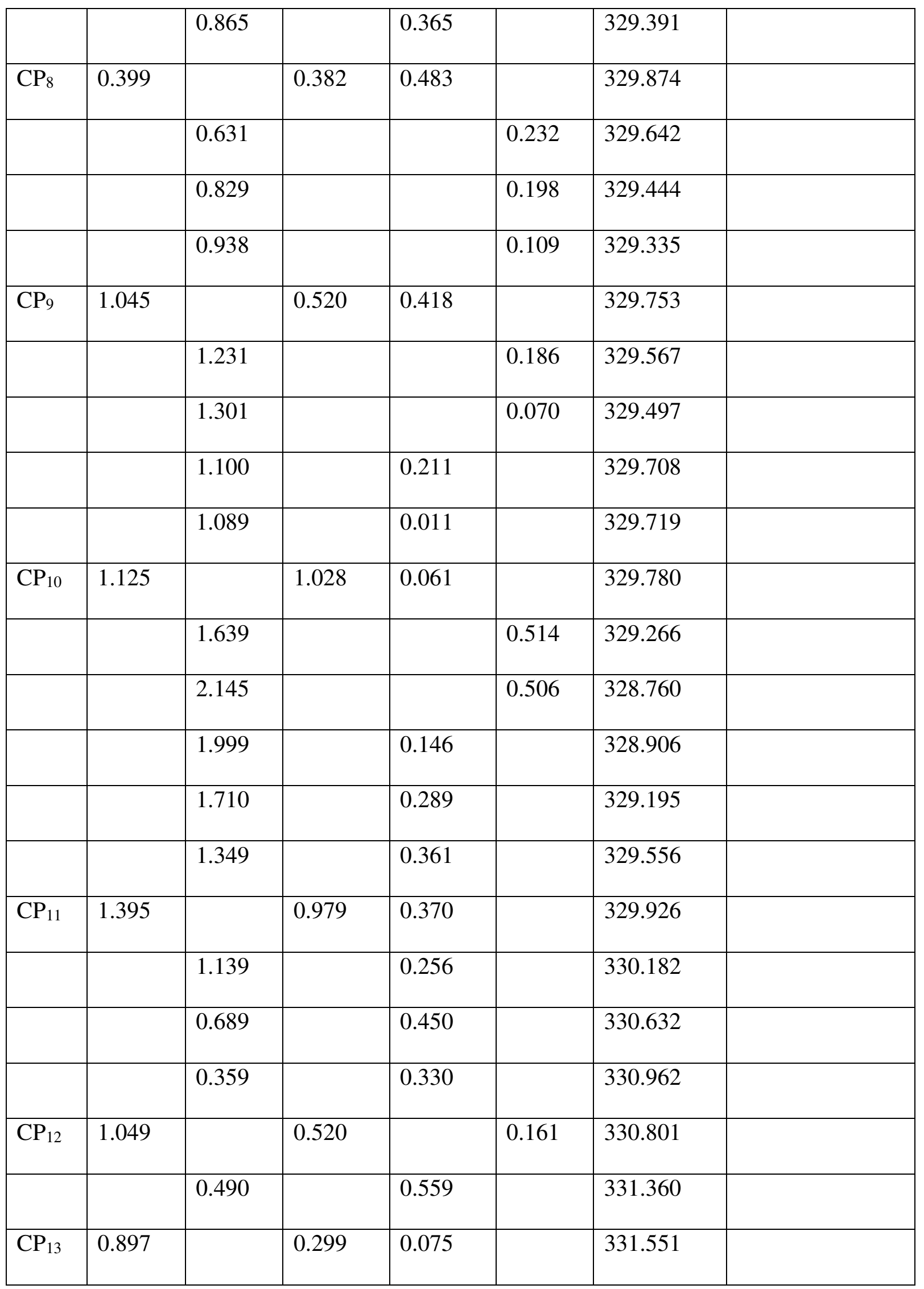




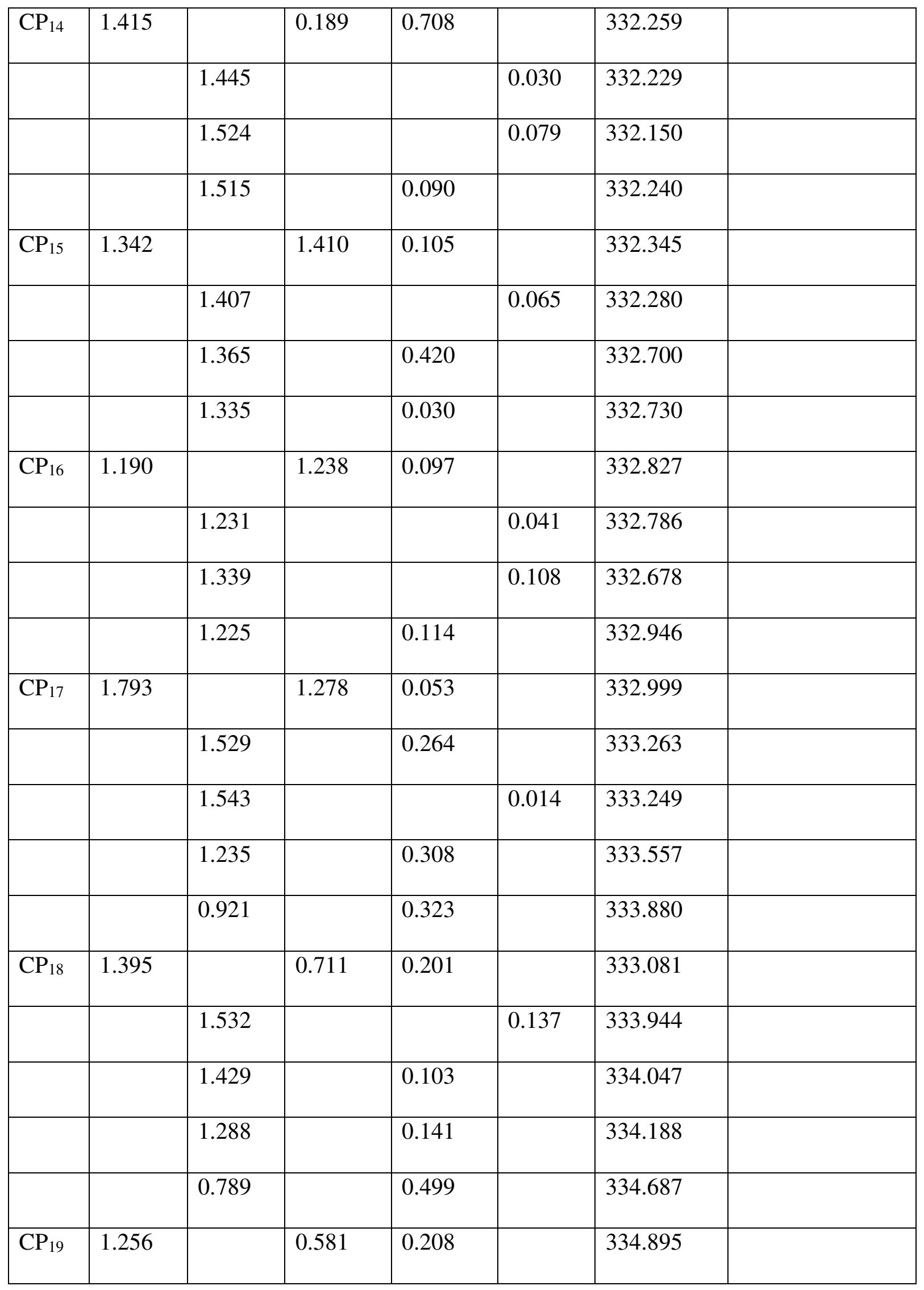




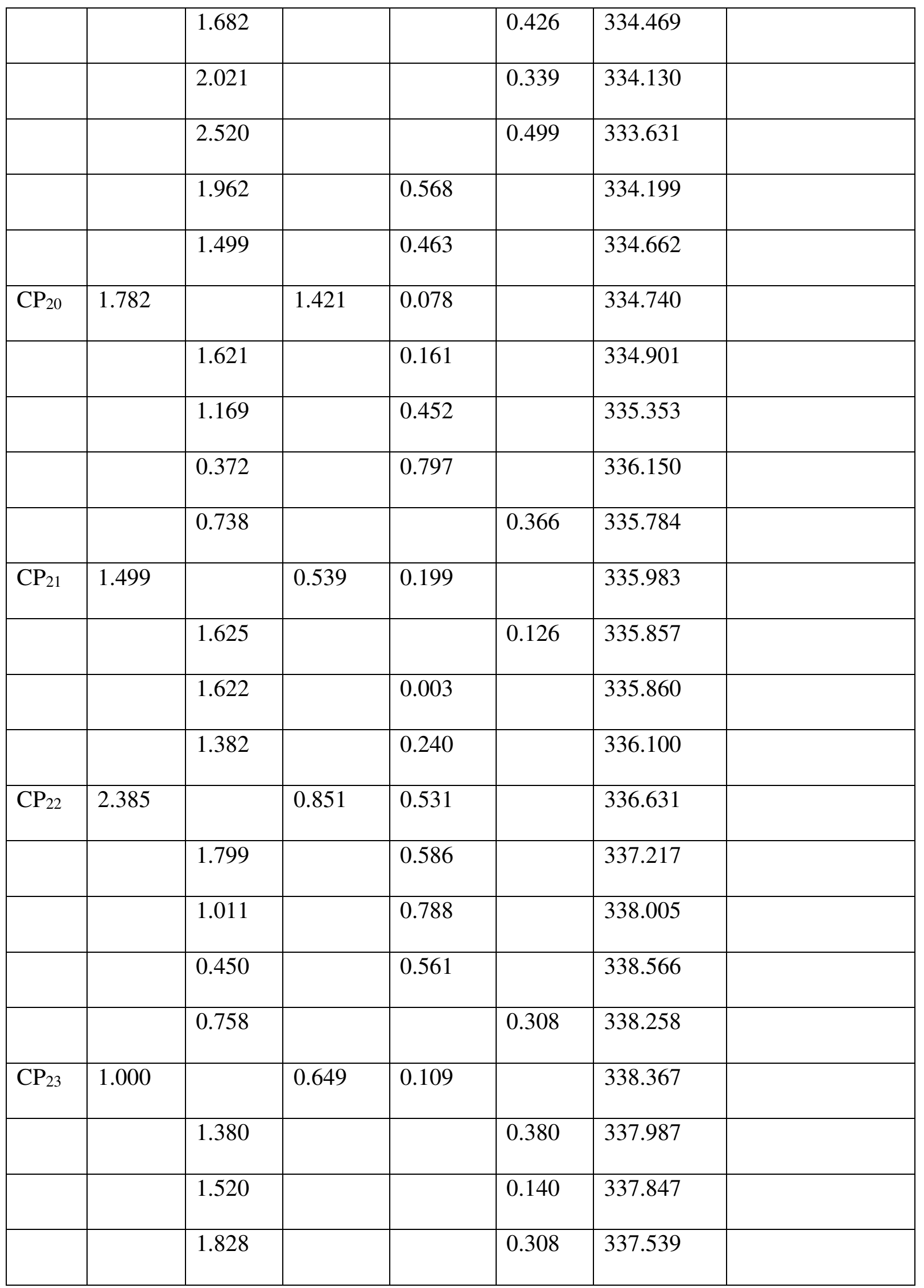




\begin{tabular}{|l|l|l|l|l|l|l|l|}
\hline & & 1.477 & & 0.351 & & 337.890 & \\
\hline $\mathrm{CP}_{24}$ & 1.482 & & 1.450 & 0.027 & & 337.917 & \\
\hline & & 1.538 & & & 0.056 & 337.981 & \\
\hline & & 1.289 & & 0.249 & & 338.232 & \\
\hline & & 0.967 & & 0.332 & & 338.554 & \\
\hline & & & 1.831 & & 0.864 & 327.690 & TBM 327.690 \\
\hline
\end{tabular}

Field Survey, 2016.

$\sum$ B.S $-\sum$ F.S $=29.980-19.390=10.590$

$\sum$ RISE $-\sum$ FALL $=18.854-8.264=10.590$

R.L last $-R \cdot L_{\text {first }}=337.690-327.100=10.590$

\section{CONCLUSION}

In conclusion, the exercise had achieved its aims, since the difference in elevation from point to point were determine and as a student, I was able to know how to read the staff from the level and also conduct a levelling exercise. 


\section{REFERENCES}

1. Pugh J. C. (1975), Surveying for field scientists, Methuen, 230pp, ISBN 0-416-07530-4.

2. Genovese I. (2005), Definition of surveying Terms, ACSM, 314pp, ISBN 0-9765991-0-4.

3. Lewis, M. J. T. (2001). Surveying Instruments. Cambridge University press. ISBN 9780521792974. Retrieved $30^{\text {th }}$ August, 2012.

4. Kahmen, Heribert; Faig, Wolfgang (1988). Surveying, Berlin, p. 9. ISBN 3-11-008303-5. retrieved 2014-08-10. 